\title{
Deep Learning Modelling of Systemic Financial Risk
}

\author{
Xianghe $\mathrm{Zhu}^{1,2}$ \\ ${ }^{1}$ School of statistics, Renmin University of China, Beijing 100872, China \\ ${ }^{2}$ Department of Basic Science, Wuchang Shouyi University, Wuhan 430064, China
}

Corresponding Author Email: zhuxianghe@ruc.edu.cn

https://doi.org/10.18280/ria.340203

Received: 17 November 2019

Accepted: 9 January 2020

\section{Keywords:}

systemic financial risk (SFR), risk prewarning, index system, deep learning $(D L)$

\begin{abstract}
This paper attempts to improve the ability to prevent systemic financial risk (SFR). Based on the generation mechanism of China's SFR, this paper presents an evaluation index system for financial risks, and then sets up a deep learning (DL) model for SFR prewarning. The proposed model inherits the merits of the DL in nonlinear approximation and selflearning, and overcomes the defects of conventional neural network (NN) model. Our model can capture the multi-dimensional changes in risk evaluation indices, and make accurate prewarning of the SFR. Our model can capture the multi-dimensional changes in risk evaluation indices, and make accurate prewarning of the SFR. Finally, empirical analysis proves that our model can retain much of the original features, and achieve highly accurate prewarning of the SFR. The research results provide technical support to risk regulation and decision-making of financial authorities.
\end{abstract}

\section{INTRODUCTION}

The financial industry in China is faced with severe challenges. On the one hand, the capital market, as economic globalization picks up speed, has fluctuated greatly multiple times, exerting a major impact on the market economy. On the other hand, some investors have suffered serious losses, due to the backward regulation measures of online finance. The number of risk points is growing in the financial sector. Against this backdrop, it is urgently needed to develop a timely and effective prewarning method for systemic financial risk (SFR), with the aim to enhance the ability of financial authorities in risk prevention [1].

The foreign research on financial risk prewarning can be traced back to the mid-to-late 1970s, triggered by the outbreak of financial crisis. As early as 1979, John F. Pilsen published his main views on currency devaluation, and pioneered in the research of financial risk prewarning. Since the subprime mortgage crisis in the US, the SFR prewarning has attracted a growing attention from relevant institutions and scholars. For example, the World Bank proposed the financial sector assessment (FSA) and risk rating models, under which the SFR is mainly calculated by credit department of each country [2]. Goldstein et al. [3] set up a prewarning index system, including 24 risk assessment indices specifically for developing countries; Among them, a composite metric of financial risk was used to describe the overall situation of the SFR. The International Monetary Fund (IMF) designed two representative index systems, namely, the macroprudential indicators (MPIs) and financial soundness indicators (FSIs), laying the basis for subsequent research [4]. Borio and Lowe [5] constructed an index system that analyzes financial imbalance from the perspectives of credit gap, asset price gap, and investment. Considering possible losses, risks, and uncertainties, Illing and Liu [6] compiled the financial stress index to measure the SFR, according to the data of Canadian banks on foreign exchange, bonds, and stock market. Borio and Drehmann [7] introduced multiple indices into the SFR index system, such as the private credit as a proportion of gross domestic product (GDP), real asset price, exchange rate and investment, as well as the prices of commercial and residential properties. Lo Duca and Peltonen [8] established the financial crisis index to prewarn the SFR.

The theoretical studies on risk prewarning techniques mainly focus on such field as food [9], automobile [10], ecology [11], and finance [12]. In China, the prewarning of financial risks $[13,14]$ mainly relies on probabilistic methods based on mathematical statistics and artificial intelligence (AI) techniques based on neural networks (NNs). For instance, some scholars examined the multi-equilibrium currency crisis with the econometric model [15]. Some scholars employed the Markov switching regimes to study the financial crisis in Europe [16], Indonesia [17], and other countries in Southeast Asia [18]. Some other scholars created a prewarning system for currency crisis, and applied the system for empirical analysis on monthly financial data from Indonesia, Malaysia, and Thailand [19]. Overall, the existing studies on financial risk prewarning emphasize on a single risk or crisis (e.g. currency crises and bank crises), failing to discuss financial risks from the internal and external environments of the financial industry.

To make up for the gap, this paper presents an evaluation index system for financial risks, in the light of the generation mechanism of China's SFR. On this basis, a deep learning (DL) model was constructed for SFR prewarning. The proposed model inherits the merits of the DL in nonlinear approximation and self-learning, and overcomes the defects of conventional NN model. Our model can capture the multidimensional changes in risk evaluation indices, and make accurate prewarning of the SFR.

The remainder of this paper is organized as follows: Section 2 proposes the evaluation index system for financial risks 
based on the features of China's SFR, and constructs the DL model for SFR prewarning; Section 3 proves the validity of our model in SFR prewarning through empirical analysis; Section 4 puts forward the conclusions of this research.

\section{METHODOLOGY}

To overcome the limitations of existing SFR prewarning methods, this paper puts forward a DL model for SFR prewarning. Firstly, an evaluation index system for financial risks was developed, in the light of the SFR features. Under the DL principle, the DL dynamic factor model was introduced to solve the numerous difficult nonlinear problems, which are common in SFR prewarning and prediction, and to realize accurate prewarning of the SFR in real time.

\subsection{SFR prewarning indices}

Unlike the real economy, the financial industry mainly takes currency and negotiable securities as its main products, which are characterized by high liquidity and instability. Compared with other products, these financial products are easily affected by changes in international economy and policy. Hence, the SFR mainly covers two aspects: the international macroeconomic environment, and the operation state of financial industry. The established evaluation index system [20] is explained in Table 1 below.

Table 1. The SFR prewarning indices

\begin{tabular}{ccc}
$\begin{array}{c}\text { Composite } \\
\text { index }\end{array}$ & $\begin{array}{c}\text { Primary } \\
\text { indices }\end{array}$ & $\begin{array}{c}\text { Secondary } \\
\text { indices }\end{array}$ \\
\hline SFR & $\begin{array}{c}\text { International } \\
\text { macroeconomic } \\
\text { environment }\end{array}$ & $\begin{array}{c}\text { GDP growth rate, consumer price index (CPI), the growth rate of total fixed asset investment, urban } \\
\text { registered unemployment rate, the year-on-year growth rate of M2, domestic and foreign assets as a } \\
\text { proportion of nongovernmental financing, year-on-year growth rate of net export, and the monthly } \\
\text { standard deviation of the exchange rate of USD to RMB. }\end{array}$ \\
& $\begin{array}{c}\text { Operation state } \\
\text { of financial } \\
\text { industry }\end{array}$ & $\begin{array}{c}\text { The growth rate of total assets of banking financial institutions, monthly standard deviation of 7-day } \\
\text { interbank lending rate, the growth rate of insurance industry assets, the growth rate of insurance } \\
\text { industry compensation, the ratio of non-performing loans of commercial banks, interbank assets as a } \\
\text { proportion of total assets, price earning (PE) ratios of Shanghai Stock Exchange (SHSE) and } \\
\text { Shenzhen Stock Exchange (SZSE), and monthly standard deviations of SHSE and SZSE. }\end{array}$ \\
\hline
\end{tabular}

\subsection{DL dynamic factor model}

DL uses feature-based factor combination to search for nonlinear factors and obtain the final prediction result. Its essence is to find the mathematical method of mapping function through observed data [21]. Compared with the traditional SFR prewarning models, the DL model, relying on relevant $\mathrm{AI}$ theories, rotates the input variables, creates a truncated hyperplane, and computes the coefficient terms. In this way, the DL model could fit the samples accurately, making up the defects of single dynamic factor model and the NN model in risk prewarning [22]. For effective prewarning of the SFR, this paper puts forward a DL dynamic factor model [23] (Figure 1) that captures the linear and nonlinear composite features between variables.

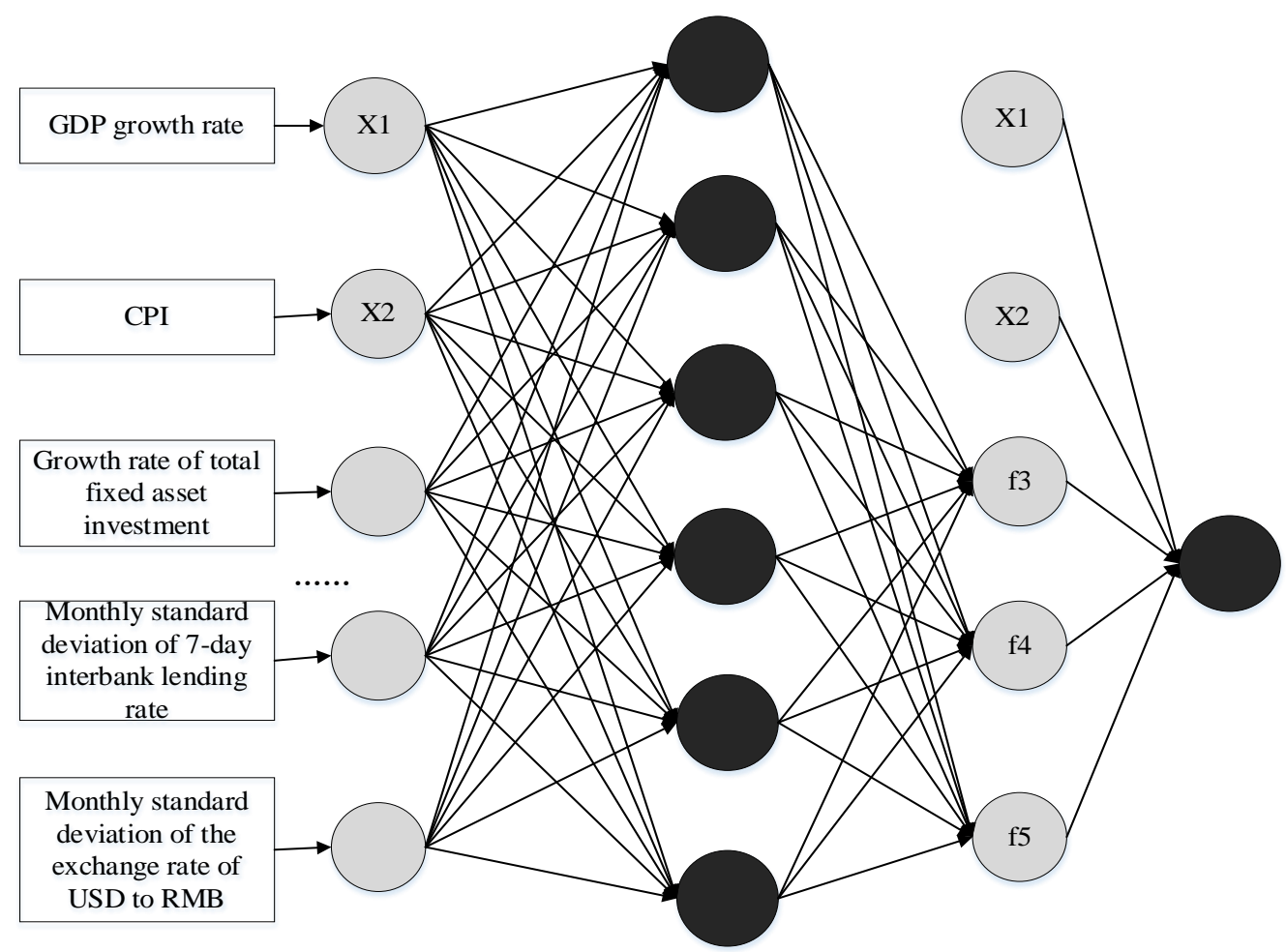

Figure 1. The DL dynamic factor model 
Let $R_{t+1} \in \boldsymbol{R}^{T \times 1}$ be the risk prewarning vector, and $X_{t} \in$ $\boldsymbol{R}^{T \times p}$ be the high-dimensional composite variable of the 16 indices in our evaluation index system. The DL is a highly nonlinear data reduction scheme using L layers of hidden factors. The formal layered model can be defined as:

$$
R_{t+1}=\alpha+\beta X_{t}+\beta_{f} F_{t}+\varepsilon_{t+1}
$$

where, $R_{t+1}$ is the linear combination of input variable $X_{t}$ and latent variable $F_{t} ; \varepsilon_{t+1}$ is a special error term of prewarning. The latent variable $F_{t}$ can be expressed as:

$$
F_{t}=F^{W, b}\left(X_{t}\right)
$$

where, $F_{t}$ is a DL reduction mapping of multivariate data; $W$ and $b$ are the weight and bias of the network parameters to be trained. Then, the function $F^{W, b}$ and $f^{W_{l}, b_{l}}$ can be expressed as:

$$
\begin{gathered}
F^{W, b}=f_{1}^{W_{1}, b_{1}} \ldots f_{L}^{W_{L}, b_{L}} \\
f^{W_{l}, b_{l}}(Z)=f_{l}\left(W_{1} Z+b_{l}\right), 1 \leq \forall l \leq L
\end{gathered}
$$

where, $f_{l}(x)$ is the activation function, which is normally $f_{l}(x)=\max (x, 0)=\operatorname{Re} L U(x)$.

\subsection{Modelling process}

According to its structure, the DL dynamic factor model needs to go through the following process to evaluate and prewarn the SFR: First, the evaluation index system should be established for financial risks through analysis on the factors affecting the risks; Second, the input variables and output variables should be determined based on the model structure; Third, the training set and rules should be determined, and the DL network training should be carried out; Fourth, the prediction result should be evaluated, and the prewarning strategies should be prepared based on the evaluation. The specific process is illustrated in Figure 2.

\section{EMPIRICAL ANALYSIS}

To verify its effectiveness, the proposed DL dynamic factor model was applied to predict China's SFR based on the recent data on macroeconomy and financial industry operations in the country. Several targeted countermeasures were presented based on the prediction results.

\subsection{Results and analysis}

The data on the SFR evaluation indices were subjected to nondimensionalization and normalization, revealing the relative trend of each index over the years. On this basis, the principal component analysis (PCA) was performed to delineate the SFR levels for prewarning and determine the corresponding value ranges of the composite risk index (Table 2). Next, the proposed DL dynamic factor model was trained with the parameters in Table 3. The trained model was applied to predict the composite risk index of the SFR in 2003-2018. Figure 3 compares the result predicted by our model with the actual SFR values. Note that the true values and predicted values are in blue and red, respectively. Obviously, our model managed to predict almost all major inflection points in real time or in advance. The predicted values show that the SFR might move upward from the valley.

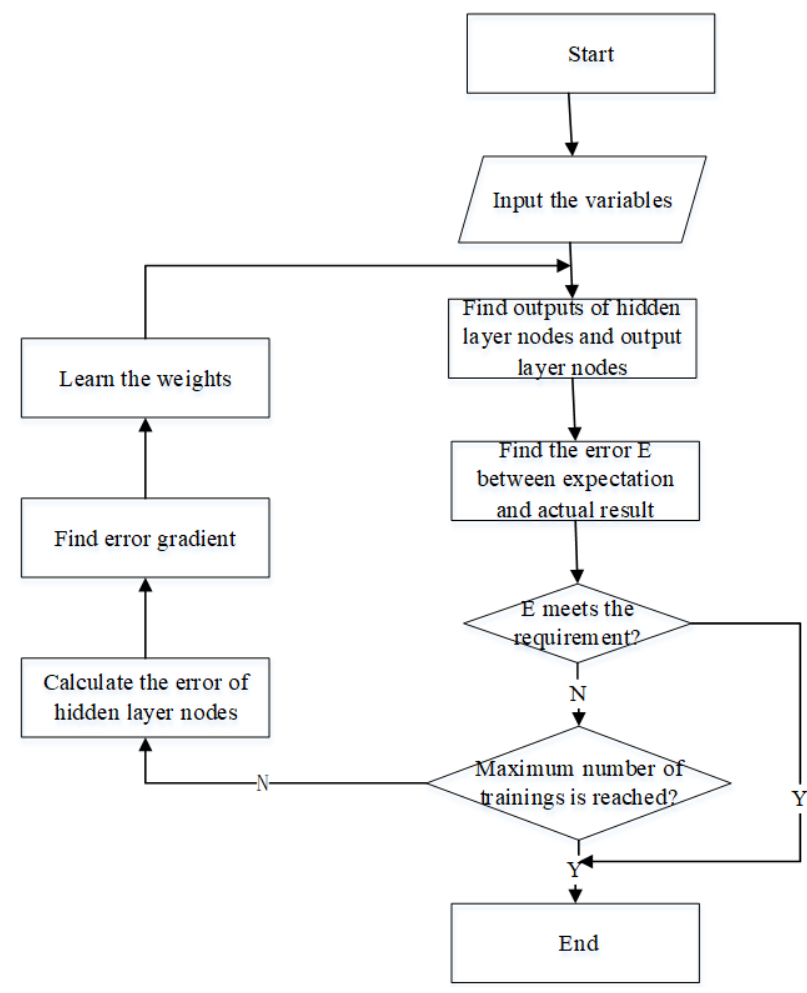

Figure 2. The modelling process

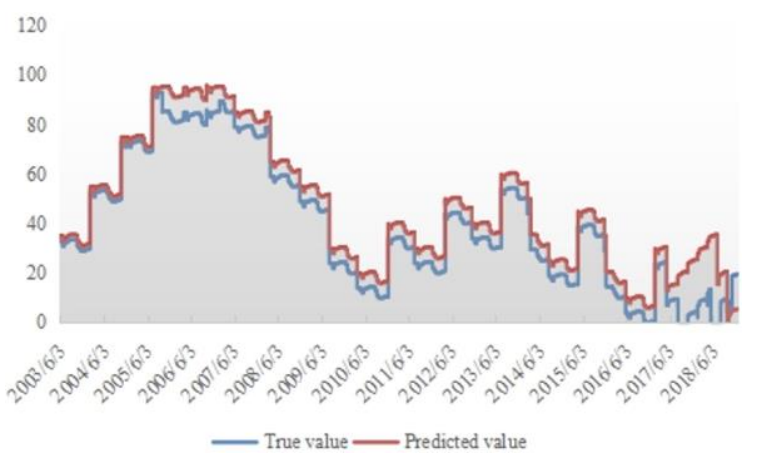

\begin{tabular}{|c|c|c|}
\hline Level Index & Value range of composite risk index & Meaning \\
\hline $\mathrm{N}_{01}$ & $<0,20>$ & Strongly low risk \\
\hline $\mathrm{N}_{02}$ & $<20,40>$ & Slightly low risk \\
\hline $\mathrm{N}_{03}$ & $<40,60>$ & Moderate risk \\
\hline $\mathrm{N}_{04}$ & $<60,80>$ & Slightly high risk \\
\hline $\mathrm{N}_{05}$ & $<80,100>$ & Strongly high risk \\
\hline
\end{tabular}

Figure 3. Comparison between predicted value and true value

Table 2. The five SFR levels and the corresponding value ranges of the composite risk index 
Table 3. Training parameters of our model

\begin{tabular}{ccccccc}
\hline Number of RNN units & Batch size & Input size & Output size & Time step & Learning rate & Number of iterations \\
\hline 10 & 6 & 25 & 1 & 4 & 0.6 & 1,000 \\
\hline
\end{tabular}

Note: RNN refers to recurrent neural network.

\subsection{Countermeasures}

The above prediction shows that the SFR in China might move upward from the valley. If the economic policy remains stable, the financial risks of China will be completely controllable. Judging by the specific risk indices, however, the weak links must be improved to prevent the SFR. Considering the existing SFR, this paper puts forward the following countermeasures:

(1) Reduce macroeconomic leverage.

To promote deleveraging, the financial regulators must effectively control the growth rate of M2, so that China's currency policy will remain stable despite further financial stimulus from developed countries. This effort also helps to promote the appreciation of the RMB.

(2) Deepen the reform of regulatory model.

The regulation methods and techniques should be upgraded continuously. The relevant laws and regulations should also be improved, creating a realistic and complete set of rules for financial regulation. In addition, the regulators must enhance their ability to regulate shadow banking business (e.g. online finance) and other emerging forms of finance.

(3) Improve the financial environment.

The judiciary department, financial regulators, and banks should form a joint work mechanism, and cooperate to crack down on debt evasion, protect lawful financial claims, strengthen the social credit system, and cultivate a trustworthy culture. Moreover, joint efforts from these organs are needed to regulate the behavior of market players, and optimize the financial environment.

\section{CONCLUSIONS}

Taking the SFR in China as the object, this paper carries out theoretical and empirically analyses on the prewarning of the SFR. Firstly, the importance of SFR prevention was demonstrated, and an index system was proposed to evaluate financial risks. On this basis, a DL dynamic factor model was proposed, and applied to predict China's SFR in 2003-2018, revealing that China's SFR was generally stable. To promote the health and stable growth of the financial industry, the authors identified the weak links in the financial system, and put forward effective countermeasures.

\section{REFERENCES}

[1] Wang, J., Yu, L. C., Lai, K. R., Zhang, X. (2016, August). Dimensional sentiment analysis using a regional $\mathrm{CNN}$ LSTM model. Proceedings of the 54th Annual Meeting of the Association for Computational Linguistics, Berlin, Germany, pp. 225-230

[2] Claessens, S., Klingebiel, D., Laeven, L. (2004). Resolving systemic financial crises: policies and institutions. World Bank Policy Research Working Paper, (3377).

[3] Goldstein, M., Kaminsky, G.L., Reinhart, C.M. (2000). Assessing financial vulnerability: An early warning system for emerging markets. Peterson Institute.

[4] International Monetary Fund Staff. (2008). Financial Soundness Indicators: Compilation Guide. International Monetary Fund.

[5] Lowe, P., Borio, C. (2002). Asset prices, financial and monetary stability: Exploring the nexus (No. 114). Bank for International Settlements.

[6] Illing, M., Liu, Y. (2006). Measuring financial stress in a developed country: An application to Canada. Journal of Financial Stability, 2(3): 243-265. https://doi.org/10.1016/j.jfs.2006.06.002

[7] Borio, C., Drehemann, M. (2010). Toward an operational framework for financial stability: 'Fuzzy' measurement and its consequences. Series on Central Banking, Analysis, and Economic Policies, no. 15.

[8] Lo Duca, M., Peltonen, T.A. (2011). Macro-Financial Vulnerabilities and Future Financial Stress-Assessing Systemic Risks and Predicting Systemic Events. ECB Working Paper Series (1311).

[9] Xiang, Y.Q., Zhang, Q.H., Han, P., Chen, M.Y. (2014). Research of early-warning expert system for security of grain storage based on uncertain inference. Applied Mechanics and Materials, 536-537: 437-442. https://doi.org/10.4028/www.scientific.net/AMM.536537.437

[10] Yousefi, A., Hadi-Vencheh, A. (2010). An integrated group decision making model and its evaluation by DEA for automobile industry. Expert Systems with Applications, $\quad 37(12)$ : 8543-8556. https://doi.org/10.1016/j.eswa.2010.05.021

[11] Shi, M.K., Peng, Y., Li, E.D., Wen, C.H. (2005). Study on early warning of ecological security in ethnic agricultural regions of the upper reaches of the pearl river-an analysis on actual examples of 22 counties within the boundary of Guizhou. China Population, Resources and Environment, 15(6): 50-54. https://doi.org/10.3969/j.issn.1002-2104.2005.06.012

[12] Bussiere, M., Fratzscher, M. (2006). Towards a new early warning system of financial crises. journal of International Money and Finance, 25(6): 953-973. https://doi.org/10.1016/j.jimonfin.2006.07.007

[13] Soomro, Z.A., Shah, M.H., Ahmed, J. (2016). Information security management needs more holistic approach: A literature review. International Journal of Information Management, 36(2): 215-225. https://doi.org/10.1016/j.ijinfomgt.2015.11.009

[14] Spanos, G., Angelis, L. (2016). The impact of information security events to the stock market: A systematic literature review. Computers \& Security, 58: 216-229. https://doi.org/10.1016/j.cose.2015.12.006

[15] Jeanne, O., Masson, P. (2000). Currency crises, sunspots and Markov-switching regimes. Journal of International Economics, 50(2): https://doi.org/10.1016/S0022-1996(99)00007-0

[16] Cerra, V., Saxena, S.C. (2002). What caused the 1991 currency crisis in India? IMF Staff Papers, 49(3): 395425. https://doi.org/10.2307/3872503

[17] Martinez-Peria, M.S. (2002). A regime switching, approach to studying speculative attacks: A focus on 
EMS crises. Empirical Economics, 27(2): 299-334. https://doi.org/10.1007/s001810100102

[18] Abiad, M.A. (2003). Early warning systems: A survey and a regime-switching approach (No. 3-32). International Monetary Fund.

[19] Nag, A., Mitra, A. (1999). Neural networks and early warning indicators of currency crisis. Reserve Bank of India Occasional Papers, 20(2): 183-222.

[20] Xu, D.L., Chen, S.L. (2014). Research on systemic financial risk early warning index system in China. BioTechnology: An Indian Journal, 10(14): 6776-6785.

[21] Uysal, F., Hardalaç, F., Koç, M. (2019). A deep learning model based on convolutional neural networks for classification of magnetic resonance prostate images. The International Conference on Artificial Intelligence and Applied Mathematics in Engineering, pp. 701-708. https://doi.org/10.1007/978-3-030-36178-5 59

[22] Hu, Y.P., Chou, R.J. (2003). A dynamic factor model. Journal of Time Series Analysis, 24: 529-538. http://dx.doi.org/10.1111/1467-9892.00320

[23] Ma, X., Hovy, E. (2016). End-to-end sequence labeling via bi-directional LSTM-CNNs-CRF. In Proceedings of the 54th Annual Meeting of the Association for Computational Linguistics, Berlin, Germany, pp. 10641074. https://doi.org/10.18653/v1/P16-1101 